\title{
THE ROLE OF RED SQUIRRELS (TAMIASCIURUS HUDSONICUS) IN SHAPING SPATIAL PATTERNS OF SEROTINY IN LODGEPOLE PINE (PINUS CONTORTA) FORESTS
}

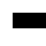

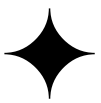

MATT V. TALLUTO $\uparrow$ CRAIG W. BENKMAN $\uparrow$ UNIVERSITY OF WYOMING $\uparrow$ LARAMIE

\begin{abstract}
$\uparrow \quad$ AbSTRACT
Understanding the effects of individual species on community- and ecosystem-level processes is of critical importance in ecology. Recent work has demonstrated that variation in genetically controlled traits within foundation species can have large implications for ecosystem processes. Identifying these traits and the selective pressures on them is crucial in understanding how ecosystems are structured and how the systems will respond to disturbance. Serotiny, the long-term storage of seeds in the canopy, is thought to be an adaptation to stand replacing fire. Seeds from serotinous plants are released following a fire, and the proportion of serotinous trees determines sapling density following a fire. The effects of serotiny are not limited to the serotinous species, as sapling density is an important determinant of plant community structure and ecosystem processes (including primary productivity and nutrient cycling). Seed predation may select against serotiny, however, no studies have addressed how the relative strengths of selection from fire and seed predation combine to produce the spatial pattern of serotiny on the landscape. Here, we report on an ongoing study of the effects of selection from seed predation in lodgepole pine (Pinus contorta), a serotinous North American conifer. Red squirrels are negatively associated with serotiny at broad geographic scales, and may select against the serotinous trait. This project examined the correlation between red squirrel density and the frequency of serotiny in lodgepole pine forests and the mechanisms underlying potential selection against serotiny by red squirrels. Specifically, we tested whether this correlation was present at landscape
\end{abstract}

scales, whether the fitness of serotinous trees was reduced in the presence of red squirrels, and what factors controlled the density of red squirrels. Preliminary results indicate that serotiny and squirrel density is negatively correlated, but only at low elevations. In the presence of squirrels, we observed significantly lower cone survival in serotinous trees, suggesting reduced fitness. Squirrel density was strongly affected by several measures of forest structure, including species composition, overhead canopy cover, and tree size (mean DBH).

\section{$\uparrow \quad$ INTRODUCTION}

It is well known that single species can have profound effects on the structure and function of communities and ecosystems. Examples include keystone species (Power et al. 1996), ecosystem engineers (Jones et al. 1994), and foundation species (Ellison et al. 2005) that affect species richness, habitat structure, and nutrient cycling (Crooks 2002, Ellison et al. 2005, Benkman et al. 2008). More recently, interest has grown in how within-species genetic variation can structure communities and ecosystems (Whitham et al. 2008, Johnson et al. 2009). By tying communities and ecosystems to heritable genetic variation within foundation species, this approach has the potential to produce quantitative predictions regarding community and ecosystem properties based on knowledge of a small number of important species (Wymore et al. 2011).

An important question is whether we can identify key traits in foundation species that have community- and ecosystem-level consequences, and 
whether we can isolate potential selective agents driving variation in these traits. If abiotic changes are superimposed on existing geographic patterns of selection due to species interactions (Thompson 2005), the result may be novel spatial patterns of selection that cascade to complex and shifting geographic mosaics in which community and ecosystem properties depend on the balance of selective forces within each patch.

Predicted future increases in fire regimes are likely to impact lodgepole pine forests (Pinus contorta) (Liu et al. 2010, Westerling et al. 2011). Furthermore, these effects will be widespread because lodgepole pine is a foundation species that dominates much of the Rocky Mountains, (Critchfield 1980). However, no studies have investigated how changes in disturbance regimes will interact with seed predation from red squirrels (Tamiasciurus hudsonicus), a seed predator that greatly reduces the canopy seed bank in lodgepole pine and may select against canopy seed storage (serotiny; see below) (Benkman and Siepielski 2004, Steele et al. 2005). Reduced canopy seed bank has been linked to lower postfire sapling densities (Tinker and Romme 1994, Schoennagel et al. 2003) and corresponding community (Turner et al. 1997) and ecosystem (Turner et al. 2004) effects. Here, we report on a study of the interactions between red squirrels and logepole pine, focusing on the potential for these interactions to produce complex spatial patterns in community and ecosystem structure. Specifically, we attempted to detect correlation between the abundance of red squirrels and the frequency of serotiny, to determine what factors influence red squirrel abundance on the landscape, to measure the strength of selection on serotiny exerted by red squirrels.

Serotiny is an adaptation to stand-replacing fire (Keeley and Zedler 1998); therefore, the spatial and temporal patterns of fire have important consequences for lodgepole pine. Moreover, serotiny is a good candidate for a trait linking the genetics of a foundation species to landscape-scale mosaics in community and ecosystem function. First, serotiny is a heritable characteristic (Critchfield 1980, Parchman et al. 2011), and \% serotiny varies, both within continuous forest patches (Tinker and Romme 1994), and among mountain ranges (Benkman and Siepielski 2004). Finally, serotiny has predictable effects on community and ecosystem properties in lodgepole pine forests. In the Greater Yellowstone Ecosystem (GYE), \% serotiny prior to widespread fires in 1988 predicted postfire seedling density (Tinker and Romme 1994, Schoennagel et al. 2003), resulting in postfire differences in community composition (Turner et al. 1997) and ecosystem processes (annual net primary productivity and leaf area index, Turner et al. 2004).

A number of studies have addressed patterns of serotiny in relation to hypothesized selective agents. Fire frequency is positively correlated with \% serotiny, and models and empirical work have suggested that increased fire frequency can select for serotiny (Perry and Lotan 1979, Gauthier et al. 1996, Enright et al. 1998, Schoennagel et al. 2003, Radeloff et al. 2004). Less attention has been given to the potential of biotic interactions to influence spatial patterns in serotiny. Seed predation could potentially have a large selective effect on serotiny, as seed storage extends a plant's vulnerability to predispersal seed predation, providing a selective advantage to plants that can either escape predation (i.e., by not being serotinous) or defend the stored seed (Janzen 1969).

In lodgepole pine, recent work has indicated that T. hudonsicus may select against serotiny (Benkman and Siepielski, 2004), suggesting that escape from predation by dispersing seeds quickly and reducing the period of vulnerability (with nonserotinous cones) may be favored in some situations. This pattern also occurs in a geographic mosaic; mountain ranges that have historically lacked red squirrels had very high frequencies of serotiny and demonstrated poor defense against seed predation. Thus, spatial patterns in serotiny are likely produced by the interplay of opposing directional selective forces from fire, favoring increased frequencies of serotiny, and from squirrels, favoring decreased frequencies of serotiny. The interaction of these two factors may therefore have considerable influence in determining community and ecosystem structure in lodgepole pine forests during postfire recovery.

We used a field study of red squirrels and lodgepole pines in Yellowstone National Park to address the general hypothesis that predation from red squirrels selects against serotiny in lodgepole pine. We focused on the following specific hypotheses: 1) There is a broad-scale negative correlation between the abundance of red squirrels and the frequency of serotiny, 2) Variation in red squirrel abundance is determined by factors other than serotiny (in other words, any correlation in hypothesis 1 is not due to red squirrels preferentially selecting low-serotiny sites), and 3) Cones on serotinous trees experience greater mortality rates than those on nonserotinous trees in the presence of predation from red squirrels. 


\section{STUDY AREA}

Our study area included mature lodgepole pine forests throughout Yellowstone National Park, focusing on the central plateau and adjacent areas. A map of plot locations is provided in Figure 1.

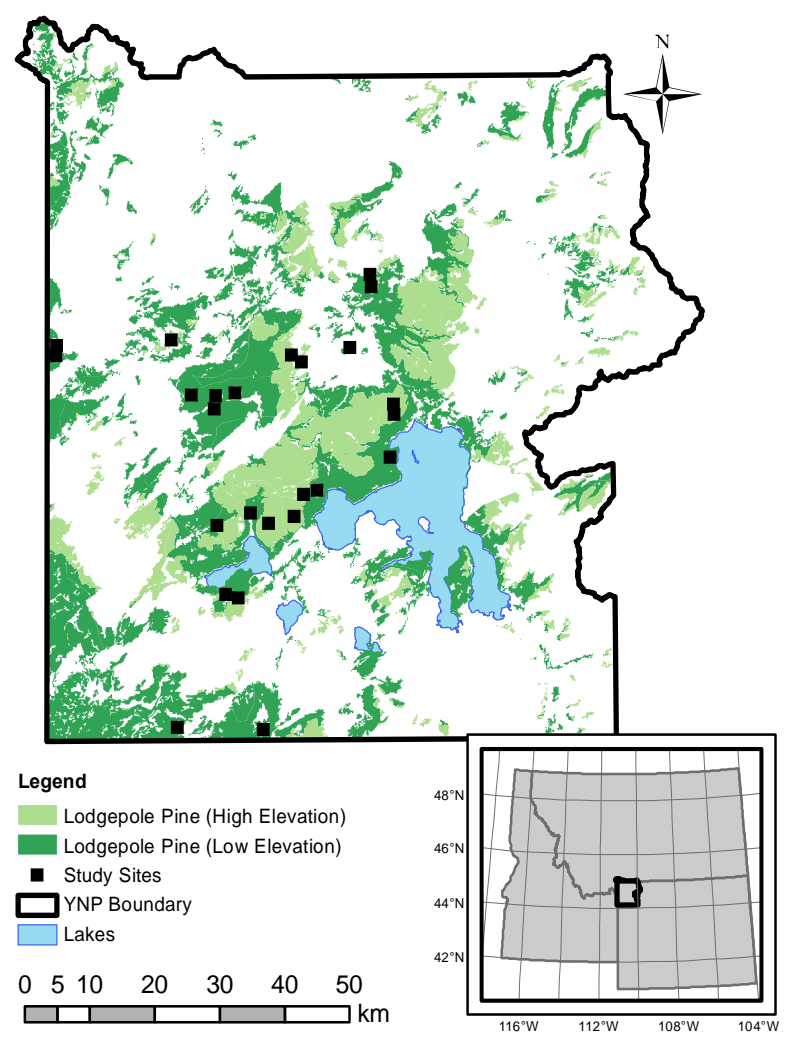

Figure 1. Location of study sites within Yellowstone National Park, along with the extent of mature lodgepole pine used for site selection.

\section{$\uparrow \quad$ METHODS}

\section{Plot Selection}

We randomly located 26 plots in mature lodgepole pine forest in Yellowstone National Park. Plots were approximately 25 ha (exact dimensions varied depending on the presence of barriers to sampling necessitating slightly smaller plots). We stratified the plots into equal numbers of high $(\geq$ $2456 \mathrm{~m})$ and low $(<2456 \mathrm{~m}$ ) elevation plots based on previous work in the region showing an elevational threshold above which serotiny is uncommon, likely due to a decrease in the frequency of stand-replacing fires at higher elevations (Schoennagel et al. 2003). Due to a GIS error, one of the low-elevation plots was excluded from the study, for a final sample size of 12 low- and 13 high-elevation plots. We sampled 14 plots in 2010 and an additional 11 plots in 2011.
Within each plot, we established 6 (2011 plots) or 8 (2010 plots) north-south oriented strip transects $(200 \times 20 \mathrm{~m})$, arranged in two rows with $150 \mathrm{~m}$ separating transect centerlines in each direction. We also established two $400-\mathrm{m}^{2}$ subplots along each transect. Subplots were located $50 \mathrm{~m}$ from the end of each transect. When transects intersected barriers (e.g., standing water, wide trails, topographic barriers) or patches dominated by species other than lodgepole pine, the transect was interrupted and continued on the other side of the barrier. If barriers intersected $>25 \%$ of a transect's total length, that transect was dropped from the plot.

\section{Red Squirrel Density}

Red squirrels are central place foragers that produce a single large midden (Smith 1968). Because each squirrel produces only one midden, we used active midden density as a proxy for squirrel density. We counted the number of middens per 0.4 ha strip transect, and converted this count into individuals/ha at the plot level.

Single observers spotted middens while walking the transect centerline, and the right angle distance from the transect centerline to the center point of each midden was measured with $5-\mathrm{cm}$ precision. Identification of active central middens was based on size $(>1 \mathrm{~m}$ in diameter) and the presence of recently chewed cone cores and scales on the top of the midden. When satellite middens were identified without an accompanying central midden, we left the transect line and attempted to locate the central midden. When estimating squirrel density, we only counted active middens that were within $20 \mathrm{~m}$ of the transect centerline.

\section{Frequency of Serotiny}

To estimate $\%$ serotiny, we recorded the number of serotinous and non-serotinous trees within each $400-\mathrm{m}^{2}$ subplot. If a subplot contained fewer than 20 trees, we counted the closest 20 trees to the subplot center. We classified trees into four categories based on the number of mature, non-weathered (i.e., brown in color) closed cones: strongly serotinous (95-100\% closed cones), weakly serotinous (50-95\% closed cones), weakly non-serotinous $(5-50 \%$ closed cones), and strongly non-serotinous (0-5\% closed cones). In practice, most trees were strongly serotinous or strongly non-serotinous; therefore, for analysis, we considered both weakly and strongly serotinous trees as serotinous, and all other trees as non-serotinous. 


\section{Forest Structure}

To determine what aspects of forest structure influenced squirrel density, we measured several aspects of forest structure within each 400- $\mathrm{m}^{2}$ subplot. We measured overhead canopy cover at five points spaced $5 \mathrm{~m}$ apart using a Forestry Suppliers Model A Spherical Crown Densiometer. We made a single measurement of basal area at the plot center using a 2.0 BAF basal area prism. Finally, we recorded the species and diameter at breast height (DBH) for the 20 trees closest to the plot center that exceeded $10 \mathrm{~cm}$ DBH. In addition to these field measurements, we included GIS-based data for mean annual precipitation, slope and aspect in our analysis of squirrel habitat.

\section{Differential Cone Mortality}

To determine whether squirrels exert selection on serotiny, we measured individual cone survival for serotinous and nonserotinous trees at a single site. During August 2010, when green cones were large enough to be easily spotted but not yet ripe enough to be removed by squirrels, we marked 187 trees within $43 \mathrm{~m}$ of active squirrel middens in an area with moderate squirrel density and moderate serotiny. We photographed branches with green cones from each tree. Because predation rates for serotinous trees vary with cone age (Smith 1970), we also photographed branches with young (i.e., brown) and older (i.e., gray) serotinous cones. In July 2011, we returned to these trees and used the photographs to determine the proportion of cones lost due to squirrel mortality.

\section{Data Analysis}

For all analyses that compared multiple models, we calculated Akaike's Information Criterion, adjusted for small samples sizes (AICc) as well as $\triangle \mathrm{AICc}$ values and the associated model weights. These model weights can be interpreted as the probability that a given model in a set is the best model in the set (Burnham and Anderson 2002). We considered a single model in a set to be superior when $\triangle \mathrm{AICc}>10$ for all other models in the set. In this case, we interpreted the best model and ignored all others. All analyses were performed using the $\mathrm{R}$ software package (R Development Core Team 2012).

To describe the correlation between red squirrel density and \% serotiny, we used generalized linear models (GLMs) with binomial errors and logit link functions. Previous studies have analyzed the effects of physical factors (e.g., soils, topography) on
$\%$ serotiny and found no clear relationships (except for elevation, see below) (Tinker and Romme 1994), therefore we excluded these factors from our analysis and focused only on the relationship between squirrel density and serotiny. Preliminary analyses of data obtained in 2010 suggested that this relationship might differ at high and low elevations, so we also included elevation as a factor with two levels (low and high) in our analysis. We compared a total of four models: squirrel density only, elevation only, squirrel density + elevation (additive model), and squirrel density * elevation (interaction model).

For the analysis of squirrel habitat, we used principal components analysis (PCA) to reduce the number of variables and eliminate correlations among predictor variables. We included 7 variables describing habitat structure as well as local climate and topography in the PCA (northern exposure, eastern exposure, precipitation, overhead canopy cover, mean $\mathrm{DBH}, \% \mathrm{CV}$ of $\mathrm{DBH}, \%$ cover of lodgepole pine, and $\%$ cover of Pinus albicaulis whitebark pine), and retained for analysis all axes with eigenvalues $>1$. We then included the retained PCA axes in GLMs with squirrel density as the response.

Because serotiny was uncommon at high elevations, we initially used the high elevation data ( $\mathrm{n}$ $=12$ ) to construct a model describing squirrel density in the absence of variation in \% serotiny. To test whether squirrel density varies independently of serotiny, we then built two models using the lowelevation data: one containing the same predictors as the most supported high-elevation model, and a second model that included those predictors as well as \% serotiny. We then used analysis of variance (ANOVA) to test the hypothesis that the more complex model was not an improvement over the simpler model.

To compare cone mortality between serotinous and non-serotinous trees, we compared cone mortality across cone types. Because cone mortality in serotinous cones varies with cone age (Smith 1970), we categorized cone type based on the degree of weathering, evident by the color of the scale. Cones were categorized as either nonserotinous, serotinous-green (< 1 year old), serotinous-brown (1-approx 5 years), and serotinousgrey (> 5 years old). We then used a $\chi^{2}$ goodness of fit test on the hypothesis that cone mortality rates were equal among groups. 


\section{$\downarrow \quad$ RESULTS}

We observed a strong negative relationship between squirrel density and percent serotiny, but only at low elevations (Figure 2). The model including both squirrel density, elevation (as a categorical variable), and their interaction was the most strongly supported model $(\triangle \mathrm{AICc}=0$, weight $=1)$, and the next closest model had essentially no support $(\triangle \mathrm{AICc}=36.8$, weight $=0)$.

For the analysis of factors controlling squirrel density, we retained the first four principal components, which explained a total of $82 \%$ of the variance in the original dataset. PC3 and PC4 did not explain any of the variance in squirrel density in any of our models, so we focus further discussion solely on PC1 and PC2, which together explained 54\% of the variance in the original dataset.

PC1 primarily described species composition, with a positive correlation with \% lodgepole pine cover and a negative correlation with $\%$ whitebark pine cover. PC1 was also negatively correlated with mean annual precipitation, which is unsurprising given the tendency for whitebark pine to occur on drier high-elevation slopes. PC2 described canopy and understory structure, and was negatively correlated with overhead canopy cover, mean DBH of all trees, and the \%CV in DBH of all trees. This axis was also positively correlated with northern and western exposure.

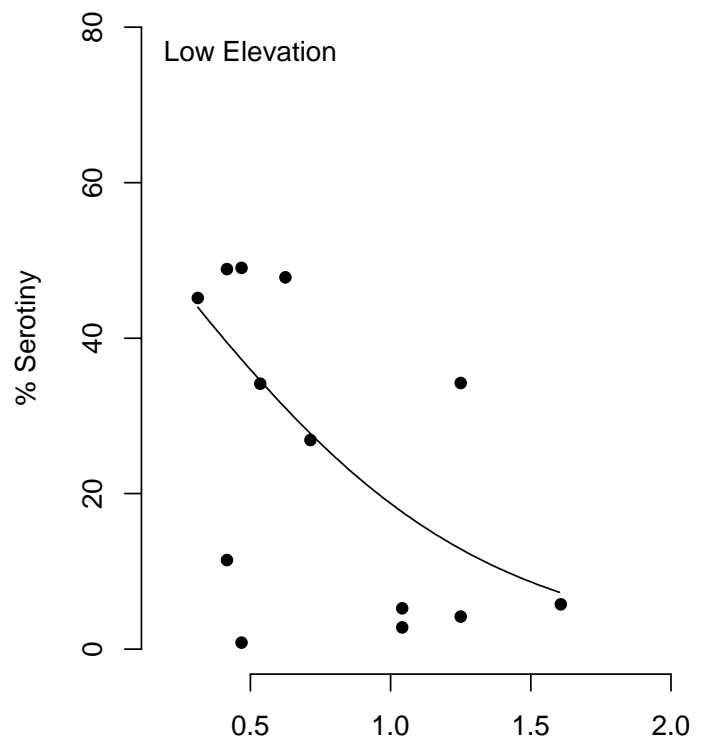

A model with PC1 and PC2 as predictors explained $78 \%$ of the variance in squirrel density at high elevations, and had greater support (i.e., minimum AICc) than any other models in the model set. Using the same model at low elevations, PC1 was not significant (likely due to a lack of whitebark pine at low elevations), but a model including only PC2 as a predictor explained $33 \%$ of the variation in squirrel density. Furthermore, the parameter estimates in both the high- and low-elevation models were similar, suggesting that similar processes control squirrel density regardless of elevation. Finally, adding \% serotiny as a predictor to the low elevation model did not significantly improve the fit of the model $(F=$ 2.14, $P=0.18$ ), indicating that serotiny does not control squirrel density.

We found that annual survival of first-year serotinous cones was significantly lower than that of non-serotinous cones (serotinous survival $=0.23$, non-serotinous survival $=0.44, \chi 2$ test $\mathrm{P}<0.001$ ), demonstrating that squirrels can greatly reduce seed survival, and that predation has a larger impact on serotinous trees. Survival was higher in older serotinous cones (brown cone survival $=0.63$, gray cone survival $=0.78$ ). However, because predation is cumulative, the probability of a serotinous cone surviving long enough to disperse its seeds is relatively low.

Squirrel Density (individuals/ha)

Figure 2. The relationship between squirrel density and the frequency of serotiny at low and high elevations. 


\section{MANAGEMENT IMPLICATIONS}

The frequency of serotiny has a large effect on postfire recovery in lodgepole pine forests; previous research has shown that seedling densities following a stand replacing fires are several orders of magnitude higher in highly serotinous stands (Turner et al. 2003). Thus, serotiny is a keystone trait, in that its frequency determines seedling density, which cascades to a number of ecosystem- and communitylevel processes (Turner et al. 2004). If the intensity of predation from red squirrels affects the frequency of serotiny at relatively local (i.e., < 100 ha) scales, then understanding how squirrels affect serotiny and what factors determine predation intensity can yield important predictive information about how forests will respond to fire. This information can be used to construct a model predicting the frequency of serotiny that incorporates input from both fire frequency and squirrel predation intensity. Furthermore, if climate change is expected to drive changes in fire frequency or in the distribution of red squirrels, such changes can be incorporated into the model to investigate future expected changes to the distribution of serotiny on the landscape and thus to the expected outcome of stand-replacing fires.

\section{$\uparrow \quad$ ACKNOWLEDGEMENTS}

Funding for this project was provided by the American Society of Mammalogists, the UWNPS Small Grants Program, the Program in Ecology and the Department of Zoology and Physiology at the University of Wyoming, and University of Wyoming Foundation. We are also grateful to the research office at Yellowstone National Park for extensive logistical support.

\section{$\uparrow \quad$ Literature Cited}

Benkman CW, Siepielski AM. 2004. A keystone selective agent? Pine squirrels and the frequency of serotiny in lodgepole pine. Ecology. 85:2082-2087

Benkman CW, Siepielski AM, Parchman TL. 2008. The local introduction of strongly interacting species and the loss of geographic variation in species and species interactions. Molecular Ecology. 17:395404.
Burnham KP, Anderson DR. Model selection and multimodel inference: a practical information-theoretic approach. 2nd ed. New York: Springer. 2002.

Critchfield WB. 1980. Genetics of Lodgepole Pine. United States Forest Service Research Paper WO-37.

Crooks JA. 2002. Characterizing ecosystem-level consequences of biological invasions: the role of ecosystem engineers. Oikos 97:153166.

Ellison AM, Bank MS, Clinton BD, Colburn EA, Elliott K, Ford CR, Foster DR, Kloeppel BD, Knoepp JD, Lovett et al. 2005. Loss of Foundation Species: Consequences for the Structure and Dynamics of Forested Ecosystems. Frontiers in Ecology and Environment. 3:479.

Enright NJ, Marsula R, Lamont BB, Wissel C. 1998. The ecological significance of canopy seed storage in fire-prone environments: a model for non-sprouting shrubs. Journal of Ecology. 86:946-959.

Gauthier S, Bergeron Y, Simon JP. 1996. Effects of fire regime on the serotiny level of jack pine. Journal of Ecology 84:539-548.

Janzen D. 1969. Seed-eaters versus seed size, number, toxicity and dispersal. Evolution. 23:1-27.

Johnson MTJ, Vellend M, Stinchcombe JR. 2009. Evolution in plant populations as a driver of ecological changes in arthropod communities. Philos T Royal Society B 364:1593-1605.

Jones CG, Lawton JH, Shachak M. 1994. Organisms as ecosystem engineers. Oikos 69:373-386.

Keeley JE, Zedler PH. Evolution of life histories in Pinus. In: Ecology and biogeography of Pinus. Cambridge, UK. Cambridge University Press, 1998. pp 219-249.

Liu Y, Stanturf J, Goodrick S. 2010. Trends in global wildfire potential in a changing climate. Forest Ecology Management. 259:685-697. 
Parchman TL, Gompert Z, Mudge J, Schilkey FD, Benkman CW, Buerkle CA. 2011. Genomewide association genetics of an adaptive trait in lodgepole pine. In revision. Molecular Ecology.

Perry DA, Lotan JE. 1979. A model of fire selection for serotiny in lodgepole pine. Evolution 33:958-968.

Power M, Tilman D, Estes J, Menge B, Bond W, Mills L, Daily G, Castilla J, Lubchenco J, Paine R. 1996. Challenges in the quest for keystones. BioScience. 46:609-620.

R Development Core Team. 2012. R: A language and environment for statistical computing. $\mathrm{R}$ Foundation for Statistical Computing, Vienna, Austria. ISBN 3-900051-07-0, URL http://www.R-project.org/.

Radeloff V, Mladenoff DJ, Guries RP, Boyce MS. 2004. Spatial patterns of cone serotiny in Pinus banksiana in relation to fire disturbance. Forest Ecology Management. 189:133-141.

Schoennagel T, Turner MG, Romme WH. 2003. The influence of fire interval and serotiny on postfire lodgepole pine density in Yellowstone National Park. Ecology 84:2967-2978.

Smith CC. 1968. The adaptive nature of social organization in the genus of three squirrels Tamiasciurus. Ecological Monographs. 38(1):31-63.

Smith CC. 1970. The coevolution of pine squirrels (Tamiasciurus) and conifers. Ecological Monographs. 40:349-371.

Steele M, Wauters LA, Larsen KW. Selection, predation and dispersal of seeds by tree squirrels in temperate and boreal forests: are the tree squirrels keystone granivores? In: Fogert PM, Hulme LJE, Vander SB. Seed fate: predation, dispersal and seedling establishment. Wallingford, Oxfordshire, UK: CABI Pub. 2005. p 205-221.
Thompson JN. The Geographic Mosaic of Coevolution. Chicago, IL: The University of Chicago Press; 2005.

Tinker DB, Romme WH, Hargrove WW, et al. 1994. Landscape-scale heterogeneity in lodgepole pine serotiny. Canadian Journal of Forest Research. 24:897-903.

Turner, MG, Romme WH, Gardner RH, Hargrove WW. 1997. Effects of fire size and pattern on early succession in Yellowstone National Park. Ecological Monographs. 67:411-433.

Turner MG, Romme WH, Tinker DB. 2003. Surprises and lessons from the 1988 Yellowstone fires. Frontiers in Ecology and the Enviroment. 1:351-358.

Turner MG, Tinker DB, Romme WH, Kashain DM, LiHon CM. 2004. Landscape patterns of sapling density, leaf area, and aboveground net primary production in postfire lodgepole pine forests, Yellowstone National Park (USA). Ecosystems. 7:751-775.

Westerling AL, Turner MG, Smithwick EAH, Romme WH, Ryan MG. 2011. Continued warming could transform Greater Yellowstone fire regimes by mid-21st century. PNAS 108:13165-13170.

Whitham TG, Difazio SP, Schweitzer JA, Shuster SM, Allan GJ, Bailey JK, Woolbright SA. 2008. Extending genomics to natural communities and ecosystems. Science 320:492-495.

Wymore AS, Keeley ATH, Yturralde KM, Schroer, ML, Propper CR, Whitham TG. 2011. Genes to ecosystems: exploring the frontiers of ecology with one of the smallest biological units. New Phytologist. 191:19-36. 